\title{
Improvement of a Conceptual Model Forecasting the Level of Economic Security of Industrial Enterprise
}

\author{
Makarenko Andrii \\ Department of Accounting, Analysis, \\ Taxation and Audit \\ Zaporizhzhya National University \\ Engineering Institute \\ Zaporizhzhya, Ukraine \\ https://orcid.org/0000-0002-9576-928X
}

\author{
Melikhova Tetiana \\ Department of Accounting, Analysis, \\ Taxation and Audit \\ Zaporizhzhya National University \\ Engineering Institute \\ Zaporizhzhya, Ukraine \\ https://orcid.org/0000-0002-9934-8722
}

\author{
Merzhynskyi Yevhenii \\ Department of economics and \\ information technologies \\ Zaporizhzhya National University \\ Engineering Institute \\ Zaporizhzhya, Ukraine \\ http://orcid.org/0000-0002-4372-889X
}

\begin{abstract}
The conceptual model of forecasting of an industrial enterprise economic security with the purpose of identifying and negative tendencies timely warnings is improved in the article. The conceptual model is based on the synthesis of the Kohonen neural network for the classification of economic security levels and the predictive neural network model. This allows the complex task of adapting the values of the indicators to improve the level of economic security of an industrial enterprise. The theoretical and practical significance of the research is the ability to use the results to develop and implement a sustainable enterprise development strategy based on the adaptive formation of economic security levels.
\end{abstract}

Keywords - adaptive management, enterprise economic safety, neuronet network prediction model.

\section{INTRODUCTION}

Recently, many large and medium-sized industrial enterprises of the metallurgical and machine-building industries have been declared bankrupt. Therefore, current trends in the functioning and effective development of enterprises require new methods for assessing and forecasting their economic security.

Increasing the level of economic security requires companies to evaluate effectively the current situation and diagnose existing problems, diversify economic activity, search for sources of financing, and timely implementation of innovative means of increasing competitiveness.

One of the mentioned means is to improve the effective system of forecasting the level of economic security as a way of protection against the impact of internal and external threats. Therefore, the existing system of economic security at the enterprise should be supplemented by a group of factors of threats to the economic security of the enterprise, its financial situation and the probability of bankruptcy and appropriate tools, through which flexible adaptation to external influences is achieved. The basis of the instrumentation for solving the existing problems is the application of methods of economics and mathematical modeling and artificial intelligence.
Improving the effective system of forecasting the level of economic security of an industrial enterprise on the basis of a systematic approach with the use of artificial intelligence methods is a complex structural and parametric process. This is due to the fact that the initial data entering the system from different sources may be noisy, incomplete, have different formats and units of measurement, and the results are exposed to informational constraints. Thus, the identified problem requires additional study in order to develop an effective tool for evaluating and forecasting the level of economic security of enterprises.

\section{ANALYSIS OF LITERARY DATA AND RESOLVING THE PROBLEM}

The problem of increasing the stability of enterprises to prevent bankruptcy is highlighted in study[1]. The authors use a complex of economic and mathematical models to assess and analyze the stability of the enterprise in crisis conditions and tools to increase its level. However, this is not enough to assess the level of economic security of the enterprise. Also, the lack of such approaches is the fact that forecasting is based on a retrospective analysis and a linear projection of a number of dynamics of individual factors. A hint of solving this problem may be the creation of an adaptive prediction system that uses different sample inputs.

In a number of studies [2]-[6] related to the problem of forecasting the level of economic security of enterprises it is proposed to apply modern neural network modeling tools. To predict the risk of bankruptcy [2] fuzzy neural networks such as ANFIS, TSK and GMDH were proposed, and [3] developed the universal neural network ARTMAP-IC, in [4] the neural network model of bankruptcy risk management. In [5], Kohonen self-organizing maps were developed for predicting bankruptcy, which were selected as representative types for controlled and uncontrolled parameters in accordance with bankruptcy predictions. In [6], a mathematical model for forecasting the enterprise performance indicators as a part of the micro-service architecture of the enterprise management system based on the neural network for the modification, addition, and removal of forecasting services has been formed. The 
available results of the research in the above-mentioned works testify to the high efficiency of the neural network equipment, however, the issue of substantiation and systematization of the input information parameters remains unresolved.

To form an effective system of enterprise management indicators, a subsystem of classification of information [7], which arrives in the subsystem of the enterprise forecasting, is developed. But the subsystem of information classification offered in this work has its disadvantages, namely, the indicators of threats to economic security that have a significant impact on the level of economic security of enterprises are not taken into account.

In [8], it was determined that the system for forecasting the safety of a company, which is measured by the state of fuzzy, poorly structured technical indicators, has a special purpose and consists of blocks of classes of indicators, and the bases of facts of individual instances of classes. However, the application of such an approach to forecasting is limited to the requirements for taking into account external uncontrolled influences in the system of adaptive enterprise management. Objective difficulties in using such an approach are the complexity of decomposing individual instances of indicator classes in a system. This again suggests that the solution to the problem should be sought in the field of creating an adaptive forecasting system that will ensure the synthesis of financial and economic indicators.

The above information shows that the issues of forecasting the economic security of enterprises are considered in various ways in literary sources, but the proposed approaches do not cover the entire field of possible cases and circumstances with bankruptcy warnings.

Consequently, on the one hand, there is a number of models for assessing the level of economic security of enterprises, each of which has its own characteristics, advantages and disadvantages. It is empirically proven that the use of a particular model is appropriate in the presence of appropriate conditions and controlled processes. On the other hand, an effective system for forecasting the level of economic security shows how to solve such problems as, in particular, adaptation to external influences, incompleteness of available information and synthesis of indicators having different formats and units of measurement. Thus, an empty scientific research niche remains the establishment of an effective system for predicting economic security of an enterprise in the form of an appropriate conceptual model that takes into account the complex task of adapting the values of financial and economic indicators for effective assessment and improvement of the level of economic security of the enterprise.

\section{PURPOSE AND OBJECTIVES OF THE STUDY}

The aim of the study is to improve the conceptual model of forecasting the level of economic security of an industrial enterprise on the basis of adaptive control mechanisms and neural network models.

To achieve the goal, the following tasks were set:
- To analyze the basis of financial and economic indicators that affect the level of economic security of an industrial enterprise;

- To develop a neural network model of clusterization of the base of the studied enterprises on the level of economic security;

- To develop a neural network model of an adaptive system for forecasting the level of economic security of an industrial enterprise taking into account external influences and obstacles.

\section{CONCEPTUAl MOdel FOR PROMOTING THE ECONOMIC SAFETY OF THE INDUSTRIAL ENTERPRISE}

Economic security of the enterprise is an integral part of the system of higher order - the socio-economic system of the enterprise, which is characterized by the presence of external and internal environment.

Based on the mentioned above, one can conclude that the factors that influence the activities of an industrial enterprise have an impact on the system of economic security of the enterprise. Therefore, in the process of constructing a conceptual model of economic security of the enterprise, we have drawn attention to the factors of the internal and external environment, their nature and structure.

In previous studies, the authors analyzed the main indicators of the activity of 17 industrial enterprises in the field of mechanical engineering and metallurgy and substantiated the most important components of economic security.

Let us consider these indicators as indicators that have the form of a tuple:

$$
\mathrm{LES}=\langle\mathrm{EEP}, \mathrm{FPP}, \mathrm{PBP}\rangle .
$$

EEP - is a set of factors of threats to the economic security of an industrial enterprise;

FPP - are factors of the financial condition of an industrial enterprise;

PBP - is probability of bankruptcy of an industrial enterprise.

The proposed set of input factors of the financial state of the enterprise FPP is represented in the form of a vector $\mathrm{FPP}=\left(f p p_{1}, f p p_{2}, \ldots, f p p_{n}\right)$, where $\mathrm{fpp}_{\mathrm{i}}-i$ component of the vector given to the input of the neuron, $i=\overline{1, n}$.

In the process of its activities, the company is affected by external and internal threats. Based on our research, we have identified a list of threats to the economic security of industrial enterprises. According to the results of the audit of primary documents, accounting registers, inventory descriptions, concise statements, financial statements, and the study of the results of audit acts and audit reports, 17 industrial enterprises have identified seven of the most influential factors of the threats to their economic security, which could be given a cost estimate. Let us consider the set of factors of threats to the economic security of the industrial enterprises EEP in the form of the vector $\mathrm{EEP}=\left(\right.$ eep $_{1}$, eep $_{2}, \ldots$, eep $\left._{\mathrm{m}}\right)$, where eep $\mathrm{j}_{\mathrm{j}}$ is the $j$ component of 
the vector given to the input of the neuron, $j=\overline{1, m}$.

The set of bankruptcy probabilities of enterprise PBP is represented by the vector $\mathrm{PBP}=\left(\mathrm{pbp}_{1}, \mathrm{pbp}_{2}, \ldots, \mathrm{pbp} \mathrm{p}_{\mathrm{r}}\right)$, where $\mathrm{pbp}_{\mathrm{z}}$ is $\mathrm{z}$-ta component of the vector given to the input of the neuron, $\mathrm{z}=\overline{1, \mathrm{r}}$.

In this way, the set of factors proposed by us in forming the entry tuple (1) will help to qualitatively differentiate industrial enterprises at the level of economic security and provide a reliable estimate of the predicted level of economic security.

The first circuit consists of several neural network modules, each of which is a network of Kohonen [9] and is used to study the relationship of financial and economic indicators of the enterprise $<E E P, F P P, P B P>$, as well as to issue a solution to the level of economic security of the enterprise $\tilde{\mathrm{y}}(x)$ in the investigated period. Each module has its own training sample $x_{t}$, where $t$ is the number of Kohonen network modules.

Consequently, let $x$ be the input vector of the Kohonen network:

$$
\mathrm{x}=\left[\left(f p p_{1}, \ldots, f p p_{n}\right),\left(e e p_{1}, \ldots, e e p_{m}\right),\left(p b p_{1}, \ldots, p b p_{r}\right)\right]^{I}
$$

The authors propose to prognosticate the level of economic security of the enterprise with the help of an improved conceptual model, which is clearly represented in Fig. 1.

In the conceptual model built in this way, the economic security of the enterprise is considered as a complex socio-economic system, taking into account the peculiarities of the structural interrelations of its elements, the influence of these elements on the overall economic development of the enterprise.

When forming an input vector the necessary condition for effective research is their normalization:

$$
\overline{\mathrm{x}}_{f p p_{i}}=\frac{f p p_{i}}{\left\|f p p_{I}\right\|}, \overline{\mathrm{x}}_{e e p_{j}}=\frac{e e p_{j}}{\left\|e e p_{J}\right\|}, \overline{\mathrm{x}}_{p b p_{z}}=\frac{p b p_{z}}{\left\|p b p_{Z}\right\|},
$$

Where $\overline{\mathbf{x}}_{f p p_{i}}, \overline{\mathbf{X}}_{e e p_{j}}, \overline{\mathbf{x}}_{p b p_{z}}-$ normalized values of the factors of the financial state, economic efficiency of economic activity, probability of bankruptcy of the enterprise $\mathrm{i}=\overline{1, \mathrm{n}}, \mathrm{j}=\overline{1, \mathrm{~m}}, \mathrm{z}=\overline{1, \mathrm{r}}$. In the expression

$f p p_{I}=\sqrt{\sum_{i=1}^{n} f p p_{i}^{2}}, e e p_{J}=\sqrt{\sum_{j=1}^{m} e e p_{j}^{2}}, p b p_{Z}=$ $\sqrt{\sum_{z=1}^{r} p b p_{z}^{2}}$

Vector of synaptic weight coefficients for g neuron: $\omega_{g}=\left[\left(\omega_{g i}, \omega_{g j}, \omega_{g z}\right)\right], g=\overline{1, l}, \mathrm{i}=\overline{1, \mathrm{n}}, \mathrm{j}=\overline{1, \mathrm{~m}}, \mathrm{z}=\overline{1, \mathrm{r}}$

where $l$ - number of network neurons.

Neuron-winner is calculated by the formula:

$$
\begin{gathered}
\tilde{y}(x)=\arg \underset{1, l}{\max }\left(\omega_{g}^{T} x\right), \\
\max _{g} \omega_{g}^{T} x \Leftrightarrow \min \left\|x-\omega_{g}\right\|, \\
\tilde{y}(x)=\arg \min _{g}\left\|x-\omega_{g}\right\|, g=\overline{1, l},
\end{gathered}
$$

Thus, only the neuron whose vector of weights $\omega$ is closest to the input vector $\mathrm{x}$ is activated.

Let $d_{s q}$ be the lateral distance between the neuron-winner and the excited neuron. The topological axis $f$ is a unimodal lateral distance function that meets two requirements:

- $f$-symmetric with respect to the center $d_{s q}=0$;

- the amplitude $f$ monotonically decreases with the increase of the lateral distance and at $d_{s q} \rightarrow 0$.

A potential function satisfying the above conditions is the Gauss function:

$$
f(x)=\exp \left(-\frac{d_{s q}^{2}}{2 \sigma^{2}}\right), d_{s q}^{2}=\left\|t_{s}-t_{q}\right\|^{2},
$$

where $t_{q}$ - the position of the excited neuron $\mathrm{q}, t_{s}-$ the discrete position of the neuron-winner.

Both coordinates are determined in the discrete output space. The width of the topological circle $\sigma$ decreases later. If $k$ - the discrete time, then the exponential decay provides dependence.

$$
\sigma(k)=\sigma_{0} e^{-\frac{k}{\tau}}
$$

where $\tau$ - the time constant, $\sigma_{0}$ - the initial value.

Okol function:

$$
f(x)=\exp \left(-\frac{d_{s q}^{2}}{2 \sigma^{2}(k)}\right)
$$

Gradually the area is narrowing, because its width decreases. Neurons of the neighborhood will participate in the adaptation of weight factors. The purpose of such an approach is to co-operate with changing the weighing coefficients of one neuron. Adaptation of the first contour of the proposed concept consists in changing the weight coefficient depending on the input vector $x$, which corresponds to the Hebb's teaching rule: the correct connections are amplified, and the false weakens.

However, for the task of clustering on the level of economic security of the enterprise this rule is not applicable, because the target output is unknown.

The modification of the Hebb's rule consists in the use of forgetting: $\lambda\left(\gamma_{g}\right) \omega_{g}$ where $\omega_{g}-$ synaptic weighting coefficients of the neuron $\mathrm{g}, \lambda\left(\gamma_{g}\right)-$ a positive scalar function from the exit. 


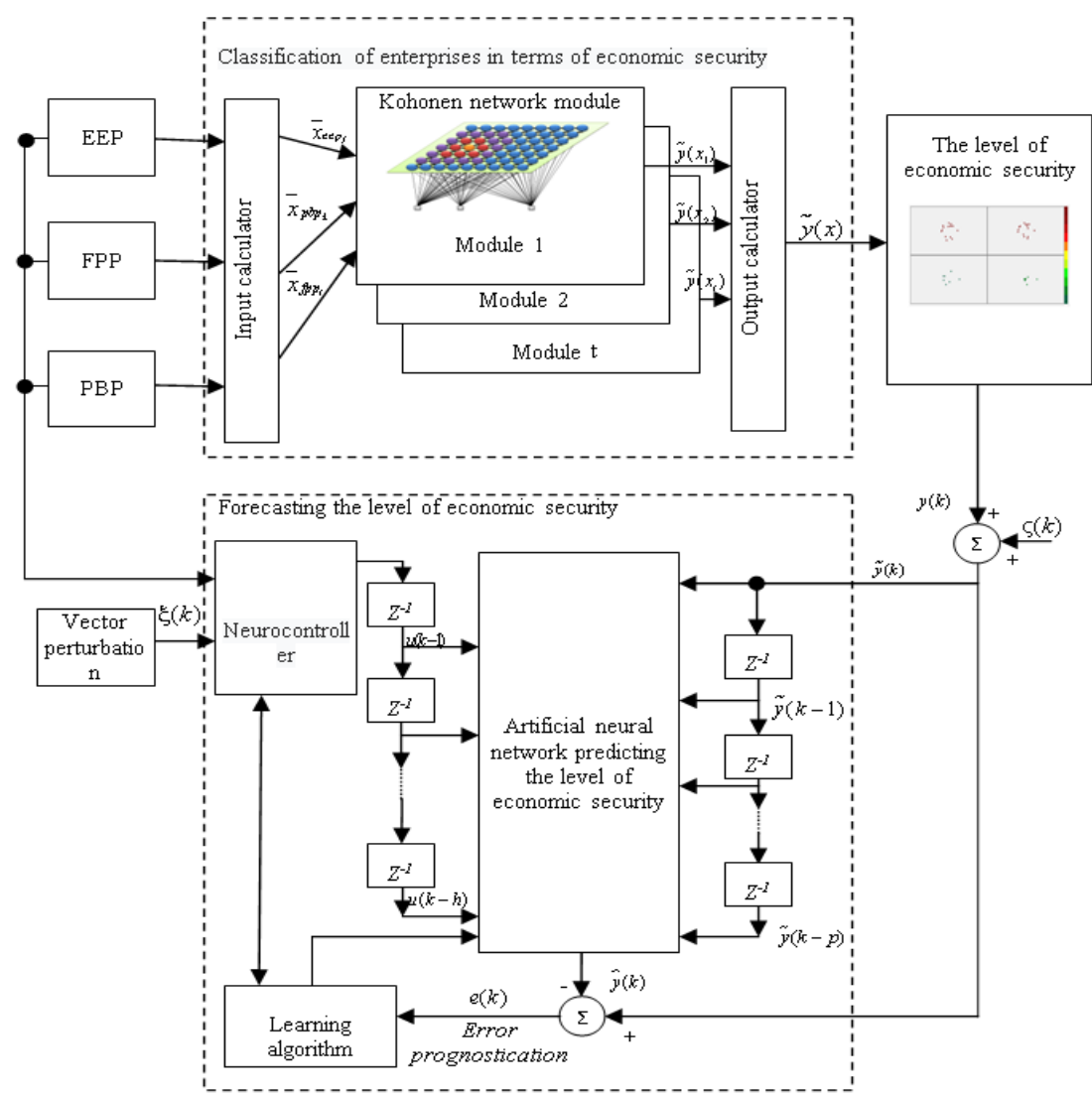

Fig. 1. Conceptual model for forecasting the level of economic security of the enterprise

The main requirement for a scalar function $\lambda\left(\gamma_{g}\right)$ is that the residual term in its expansion by the Taylor formula is equal to zero, that is:

$$
\left.\lambda\left(\gamma_{g}\right)\right|_{\gamma_{g}=0}=0
$$

We are invited to carry out the modification of weight coefficients by the following formula:

$$
\Delta \omega_{g}=\vartheta \gamma_{g} x-\lambda\left(\gamma_{g}\right) \omega_{g}
$$

where $\vartheta$ - is rate of learning.

To fulfill the condition (9), we choose a linear function $\lambda\left(\gamma_{g}\right)=\vartheta \gamma_{g}$. Then weights can be calculated using the following formula:

$$
\Delta \omega_{g}=\vartheta \gamma_{g}\left(x-\omega_{g}\right)=\vartheta f(x)\left(x-\omega_{g}\right) .
$$

Hence, in the transition from the moment of time $k$ to $k+1$, we obtain:

$$
\omega_{g}(k+1)=\omega_{g}(k)+\vartheta(k) f(k)_{k}\left(x-\omega_{g}(k)\right), g=\overline{1, l}
$$

Thus, weighing coefficients of all neurons from the vicinity of the neuron-winner $g$ are modified. The value of the weight vector $\omega_{g}$ of the neuron-winner is approaching $\mathrm{x}$.
The second contour of the conceptual model for forecasting the level of economic security of the enterprise is transmitted to the incoming information about the current levels of economic security of enterprises $y(k)$, financial and economic indicators of the enterprise $<E E P, F P P, P B P>$ and the perturbation vector $\xi(k)$, (Fig. 1.). For effective forecasting of the level of economic security of enterprises, correction of the parameters of the regulator is necessary, which provides the best management of financial and economic indicators of the enterprise's activity at some optimal point.

In this regard, the concept was supplemented by a neuro regulator, which provides adaptive adjustments, both input parameters of financial and economic activity of the enterprise, and the assessment of the effects of external obstacles. Most often, for solving the prediction problem, a multilayer perceptron and a radial-basic network are used.

Thus, the authors propose to solve the problem of forecasting the level of economic security by the following equation:

$$
\tilde{y}(k)=f[y(k-1), \ldots, y(k-p),(k-1), \ldots, u(k-h)+\varsigma(k)],
$$

where $\tilde{y}(\eta), u(\eta)$ - the output and input signals of the contour classification of enterprises in terms of economic security at the time $\eta$ correspondingly; $p, h$ - delayed orders for output and input channels respectively; $f(\cdot)$ - is an unknown nonlinear function; $\varsigma$ - noise of measurement of the output signal. 
Marking the vector of the generalized signal entering the input of the model, as:

$$
x(k)=f\left[y^{T}(k-1), \ldots, y^{T}(k-p), u^{T}(k-1), \ldots, u^{T}(k-h)\right]^{T},
$$

we rewrite the equation (12) in the form:

$$
\tilde{y}(k)=f(x(k)+\varsigma(k)) .
$$

The developed neural network model for predicting the level of economic security of an enterprise in the application of multilayer perceptron has the form:

$$
€(k)=f^{\delta}\left[\left(\omega^{\delta}\right)^{T} f^{q-1}\left[\ldots f^{1}\left[\omega^{1}\right]^{T}\right] x(k)\right],
$$

where $\delta-$ the number of layers in the network; $\omega^{i}-$ vector of weight parameters of neurons of the $i$ layer of the network; $f^{i}(\cdot)$-activation function of the $i$ layer.

The neural network model in the form of a radial-basic network, which uses some basic functions $\Phi_{i}(x)$ for approximation $f(\cdot)$ is calculated as follows:

$$
£(\mathrm{k})=\sum_{\mathrm{i}=1}^{\mathrm{N}} \mathrm{c}_{\mathrm{i}} \Phi_{\mathrm{i}}(\mathrm{x}),
$$

where $c_{i}$-weighted coefficients to be determined.

The task of management is to determine the values $u(k)$ that provide a minimum of functional:

$$
\theta(k)=\|e(k)\|^{2} .
$$

To find the functional minimum, it is expedient to use recursive algorithms, in particular gradients:

$$
u(k)=u(k-1)+\psi(k)\left[\nabla_{u}(e(k)+\xi(k))\right],
$$

where $\nabla_{u} e(k)=\frac{d e(k)}{d u(k)}, \nabla_{u} \xi(k)=\frac{d \xi(k)}{d u(k)}, \psi(k)>0$.

The training of the network for forecasting the level of economic security of the enterprise is proposed to be carried out using the BFGS algorithm [10].

The current concept will allow, on the one hand, to construct fairly simple neural network models, and on the other - to adjust adaptively the parameters of both these models and the regulator in accordance with changing conditions. To optimize the process of forecasting economic security of an enterprise in solving the task of clustering enterprises in terms of economic security, the Kohonen network or self-organizing maps (COM) are used.

Thus, the proposed conceptual model for forecasting the level of economic security may be applied in large and medium-sized enterprises of the machine-building and metallurgical industry. In the case of modification and clarification of input factors in terms of economic efficiency and financial condition, its application can be applied at enterprises of other industries.

\section{CONCLUSIONS}

The conducted research made it possible to come to following conclusions.

1. The base of financial and economic indicators of industrial enterprises is analyzed. It takes into account as a result the information base of indicators of effective functioning of the enterprise, namely: factors of economic efficiency of economic activity, financial status, probability of bankruptcy.

2. The neural network model of the base clustering of the studied enterprises according to the level of economic security is developed. Unlike others, it takes into account the multiple assessment of the level of economic security as a result of different input samples.

3. A neural network model of an adaptive system for predicting the level of economic security of an enterprise is developed, which takes into account the optimal values of the parameters of the level of economic security as a result, which accelerates the mechanisms of adaptation of the enterprise to possible threats.

Thanks to the introduction of the neural control module in the conceptual model, the neural network of forecasting of the level of economic security (13) allows solving the difficult task of adapting the values of the indicators to improve the level of economic security of the industrial enterprise.

\section{REFERENCES}

[1] L. Guryanova, et al, "Modeling of the enterprise functioning stability using the automatic control theory apparatus", Eastern-European Journal of Enterprise Technologies, vol. 4, no. 3(88), pp.45-55, 2017.

[2] Y. Zaychenko "Banks bankruptcy risk forecasting with application of FNN", in 11th International Scientific and Technical Conference CSIT, Lviv, 2016, pp. 196-199.

[3] R. Balina, S. Juszczyk "Forecasting bankruptcy risk of international commercial road transport companies", Int. J. of Management and Enterprise Development, vol. 13, pp. 1-20, 2014.

[4] R. Kachalov, and Y. Sleptsova "Application of system economic theory in neural network modeling of risk management processes", in Proceedings of the $V$ International research and practice conferencebiennale on System analysis in economics, Moscow, 2018, pp. 226228.

[5] K. Lee, D.Booth, and P.Alam, "Backpropagation and Kohonen SelfOrganizing Feature Map in Bankruptcy Prediction" in Neural Networks in Business Forecasting, G.P. Zhang, Eds. Hershey PA, USA: IRM Press, 2004, pp. 158-171.

[6] I. Oksanych, I. Shevchenko, I. Shcherbak, and S. Shcherbak "Development of specialized services for forecasting performance of the enterprise on the basis of micro-service architecture", Information Technologies, Management Systems in Industy, vol. 2, no 86, pp. 114118, 2017.

[7] M. Oklander, T. Oklander, I. Pedko, and O. Yashkina "Development of the subsystem of forecasting of the marketing information management system at the industrial enterprise", Management processes, vol. 5, no. 89, pp. 39-51, 2017.

[8] O. Chubukova, and H. Ivanchenko "Development of the system for prediction of security state of an enterprise using semantic-frame fuzzy models of knowledge base", Eastern-European Journal of Enterprise Technologies, vol 6, no. 90, pp. 58-65, 2017.

[9] M. Cottrell, B. Girard, Y. Girard, C. Muller, and P. Rousset "Daily Electrical Power Curves: Classification and Forecasting Using a Kohonen Map, From Natural to Artificial Neural Computation", Lecture Notes in Computer Science, Vol. 930, pp. 1107-1113, 1995.

[10] O. Rudenko and E. Bodianskii, Artificial Neural Networks. Kharkiv, Ukraine: Company "SMIT" Ltd, 2006. 